\title{
POPULASI KUPU-KUPU (LEPIDOPTERA ) DI PULAU MANTEHAGE, SULAWESI UTARA
}

\author{
Debry C. Lamatoa ${ }^{1)}$, Roni Koneri ${ }^{1)}$, Ratna Siahaan ${ }^{1)}$, Pience V. Maabuat ${ }^{1)}$ \\ ${ }^{1)}$ Program Studi Biologi FMIPA Universitas Sam Ratulangi \\ Jl. Kampus Unsrat, Manado 95115 \\ e-mail : ebhy.lamatoa@yahoo.com; ronicaniago@yahoo.com; \\ ratna245_siahaan@yahoo.com; Thealyn@yahoo.com
}

\begin{abstract}
ABSTRAK
Kupu-kupu berperan penting dalam ekosistem dan dapat membantu proses penyerbukan pada tumbuhan. Penelitian ini bertujuan untuk mengkaji populasi kupu-kupu di Pulau Mantehage, Sulawesi Utara. Pengambilan sampel kupu-kupu dilakukan dari Maret sampai Mei 2013 di Pulau Mantehage, Sulawesi Utara. Kupu-kupu dikoleksi dengan menggunakan metode sweeping yang diterapkan secara acak sepanjang 500m. Hasil penelitian menunjukkan bahwa kupu-kupu di Pulau Mantehage ada 19 spesies yang termasuk ke dalam 4 famili yaitu Nymphalidae, Papilionidae, Pieridae dan Riodinidae. Spesies kupu-kupu yang paling banyak ditemukan yaitu Catopsilia scylla asema. Famili yang paling banyak ditemukan yaitu Famili Nymphalidae dengan jumlah spesies sebanyak 11 spesies. Kupu-kupu yang paling sedikit yaitu Famili Riodinidae yang memiliki jumlah satu spesies.
\end{abstract}

Kata kunci : Populasi kupu-kupu, Pulau Mantehage, Sulawesi Utara.

\section{POPULATION OF BUTTERFLY (LEPIDOPTERA) IN MANTEHAGE ISLAND, NORTH SULAWESI}

\begin{abstract}
Butterfly has ecological functions for pollination and as biodicator of ecosystem change. This study was conducted for studying butterfly population in Mantehage Island, North Sulawesi. Butterfly sampling conducted in March until May 2013 in Mantehage island, North Sulawesi. Butterfly were collected by using random sweeping along $500 \mathrm{~m}$. The result showed there were 19 species in 4 families i.e. Nymphalidae, Papilionidae, Pieridae dan Riodinidae. The most commonly butterfly found was Catopsilia scylla asema. The most common family was Nymphalidae with numbers of species were 11 species. The least family was Riodinidae with only 1 species.
\end{abstract}

Keywords: Butterfly population, Mantehage Island, North Sulawesi.

\section{PENDAHULUAN}

Pulau Mantehage merupakan gugusan pulau di Semenanjung Utara Sulawesi. Secara administratif pulau tersebut termasuk Kecamatan Wori, Kabupaten Minahasa Utara. Luas daratan Pulau Mantehage 738,10 Ha dan sebagian besar bertopografi datar dan tidak terdapat perbukitan. Pulau Mantehage memiliki keanekaragaman jenis flora dan fauna. Jenis-jenis flora antara lain palma, seperti sagu/rumbia (Metroxylon sago), woka/palem kipas (Livistona chinensis), dan kelapa (Cocos nucifera). Jenis-jenis buahbuahan, seperti mangga (Mangifera indica), pisang (Musa. sp) dan berbagai jenis buahbuahan lainnya (Mehta, 1999).

Salah satu keanekaragaman fauna yang terdapat di Pulau Mantehage adalah kupukupu (Mehta, 1999). Di alam kupu-kupu memiliki peranan yang sangat penting dalam mempertahankan ekosistem, seperti membantupen yerbukan pada tumbuhan berbunga, sehingga proses perbanyakan tumbuhan secara alamiah dapat berlangsung (Borror et al., 1992). Keberadaan populasi kupu-kupu pada suatu habitat sangat bergantung pada keanekaragaman tumbuhan inang, sehingga memberikan hubungan yang erat antara keanekaragaman dengan kondisi 
habitatnya (Widhiono, 2004). Kupu-kupu merupakan bagian dari keanekaragaman hayati yang harus dijaga kelestariannya dari kepunahan maupun penurunan keanekaragaman jenisnya. Secara ekologis, kupu-kupu berperan dalam menjaga keseimbangan ekosistem dan membantu penyebaran tumbuhan, serta sebagai bioindikator kualitas lingkungan (Achmad, 2002).

Kerusakan habitat yang menyebab-kan penurunan keanekaragaman tumbuhan inang, menjadi salah satu faktor penyebab penurunan keanekaragaman kupu-kupu. Achmad (2002) menyebutkan bahwa kerusakan habitat terjadi karena aktivitas manusia dalam mengkonversi habitat alami. Selain itu, keanekaragaman kupu-kupu dipengaruhi oleh ketinggian, suhu, kelembaban, intensitas cahaya, cuaca, musim, volume, dan nektar tumbuhan.

Pulau Mantehage terfragmentasi karena perubahan bentuk tata guna lahan. Alih fungsi lahan hutan yang dibangun menjadi permukiman akan mengurangi vegetasi sebagai tumbuhan inang kupu-kupu. Perubahan ekosistem yang terjadi karena eksploitasi yang sangat cepat merupakan ancaman bagi keberadaan populasi kupukupu pada suatu ekosistem. Fragmentasi habitat tersebut dapat mempengaruhi keberadaan spesies pada suatu pulau, yaitu dengan cara membatasi potensi suatu spesies untuk menyebar seperti pergerakan dan pencarian makan, mengurangi daerah jelajah hewan asli dan kondisi lingkungan dapat berubah. Fragmentasi habitat dapat mengurangi keanekaragaman jenis dan ukuran populasi (Koneri, 2008). Kondisi tersebut jika terus berlangsung maka akan semakin menekan populasi kupu-kupu, dan pada akhirnya kupu-kupu akan mengalami kepunahan.

Penelitian tentang perubahan habitat terhadap populasi kupu-kupu di Indonesia telah banyak dilakukan. Beberapa penelitian tentang populasi kupu-kupu di Pulau Sulawesi telah dilakukan oleh Noerjito dan Amir (1992), Koneri dan Saroyo (2011), Koneri dan Saroyo (2012). Bagaimanakah populasi kupu-kupu di Pulau Mantehage? Penelitian tentang hal tersebut pada saat ini belum pernah diteliti dan dipublikasikan. Pada hal, informasi ini sangat penting mengingat pada pulau tersebut sudah terjadi alih fungsi lahan hutan menjadi pertanian dan pemukiman, sehingga akan berdampak terhadap populasi kupu-kupu. Berdasarkan hal tersebut, perlu dilakukan penelitian tentang populasi kupu-kupu di Pulau Mantehage, Sulawesi Utara. Hasil penelitian ini diharapkan dapat menjadi database tentang populasi kupu-kupu di Pulau Mantehage, Sulawesi Utara.

\section{METODOLOGI PENELITIAN}

\section{a. Waktu dan Tempat Penelitian}

Penelitian ini dilaksanakan mulai Maret sampai Mei 2013 di Pulau Mantehage, Sulawesi Utara.

\section{b. Bahan dan Cara Kerja}

Bahan dan alat yang digunakan dalam penelitian ini yaitu alkohol $70 \%$, sweepnet (jaring serangga), kertas minyak/kertas papilot, jarum suntik $5 \mathrm{ml}$, kertas label, sterofoam, GPS (Global Position System) merek Garmin, buku catatan, buku identifikasi, alat tulis, kotak koleksi, kamera, jarum pentul, termometer dan higrometer.

Teknik pengambilan sampel yang digunakan adalah teknik survei dengan pengambilan sampel secara purposive random sampling. Koleksi kupu-kupu dilakukan dengan teknik sweeping yang diterapkan secara random sepanjang $500 \mathrm{~m}$ dan jarak antar transek yaitu $200 \mathrm{~m}$. Jumlah transek yang dibuat sebanyak 4 garis transek dengan jumlah ulangan sebanyak 2 kali ulangan. Pengambilan sampel dilaksanakan dari jam 08.00 sampai 15.00 WITA. Pengambilan sampel kupu-kupu yang dikoleksi hanya satu spesimen setiap spesies. Bila ditemukan spesies yang sama jenis maka kupu-kupu tersebut akan dilepas kembali, untuk mencegah kemungkinan terjadinya perhitungan ganda (lebih dari satu). Spesimen yang ditangkap lalu disuntik dengan menggunakan alkohol $70 \%$ pada bagian toraks. Setelah itu, spesimen dimasukkan ke dalam kertas papilot dan diberi label sebagai penanda. Spesimen yang ditangkap kemudian diidentifikasi di Laboratorium Ekologi dan Biokonservasi, Jurusan Biologi, FMIPA Unsrat..

Buku identifikasi yang dipakai yaitu Butterflies of the South East Asian Island, Part I Papilionidae, Part II Pieridae-Danaidae, 
Part III Satyridae-Lybytheidae, Part IV Nympalidae (I), Part V Nympalidae (II) (Tsukada \& Nishiyama, 1982:1981;1982;1985;1991), serangga Taman Nasional Gunung Halimun Jawa Bagian Barat (Amir et al., 2003), panduan praktis kupu-kupu di kebun Raya Bogor (Peggie dan Amir, 2006), dan Entomologi Pertanian (Jumar, 2000).

\section{HASIL DAN PEMBAHASAN}

Hasil penelitian didapatkan sebanyak 332 individu yang tergolong dalam 19 spesies kupu-kupu (Lepidoptera) (Tabel 1). Kupukupu yang diperoleh terdiri dari 4 famili yaitu, Famili Nymphalidae (57,89\%), Papilionidae (21,05\%), Pieridae (15,79\%) dan Riodinidae (5,26\%) (Gambar 1). Famili Nymphalidae terdiri dari 10 genus dan 11 spesies, Famili Papilionidae (2 genus dan 4 spesies), Famili Pieridae (satu genus dan 3 spesies) dan Famili Riodinidae yang hanya memiliki satu spesies dan satu genus (Gambar 2). Jumlah genus yang ditemukan sebanyak 14 genus dan genus yang memiliki spesies terbanyak adalah Papilo. Spesies kupu-kupu yang memiliki kelimpahan tertinggi yaitu Catopsilia scylla asema $(16,57 \%)$ dan Catopsilia pamona flava $(15,06 \%)$. Sedangkan spesies yang kelimpahannya yang terendah adalah Danaus ismare alba, Lohara dexamenus dan Graphium agamemnon dengan masingmasing jumlah individu sebanyak satu individu $(0,30 \%)$ (Tabel 1).
Tabel 1. Jumlah Famili dan Spesies yang Ditemukan di Pulau Mantehage, Sulawesi Utara

\begin{tabular}{|c|c|c|c|}
\hline No & Famili/Spesies & Jlh & $\%$ \\
\hline I & Nymphalidae & & \\
\hline 1 & Junonia hedonia intermedia & 31 & 9,34 \\
\hline 2 & Hypolimnas bolina & 30 & 9,04 \\
\hline 3 & Ideopsis juventa tontoliensis & 28 & 8,43 \\
\hline 4 & Hypolimnas missipus & 10 & 3,01 \\
\hline 5 & Acrophtalmia windorum & 8 & 2,41 \\
\hline 6 & Euploea leucotictos westwoodi & 6 & 1,81 \\
\hline 7 & Euploea algae horsfieldi & 6 & 1,81 \\
\hline 8 & Lasippa neriphus tawayana & 6 & 1,81 \\
\hline 9 & Melanitis leda obsoleta & 2 & 0,60 \\
\hline 10 & Lohara dexamenus & 1 & 0,30 \\
\hline 11 & Danaus ismare alba & 1 & 0,30 \\
\hline II & Papilionidae & & \\
\hline 12 & Papilio demoleus & 32 & 9,64 \\
\hline 13 & Papilio gigon & 19 & 5,72 \\
\hline 14 & Papilio sataspes & 3 & 0,90 \\
\hline 15 & Graphium agamemnon & 1 & 0,30 \\
\hline III & Pieridae & & \\
\hline 16 & Catopsilia scylla asema & 55 & 16,57 \\
\hline 17 & Catopsilia pamona flava & 50 & 15,06 \\
\hline 18 & Eurema tomina & 27 & 8,13 \\
\hline IV & Riodinidae & & \\
\hline 19 & Abisara echerius & 16 & 4,82 \\
\hline Total & & 332 & 100,00 \\
\hline
\end{tabular}

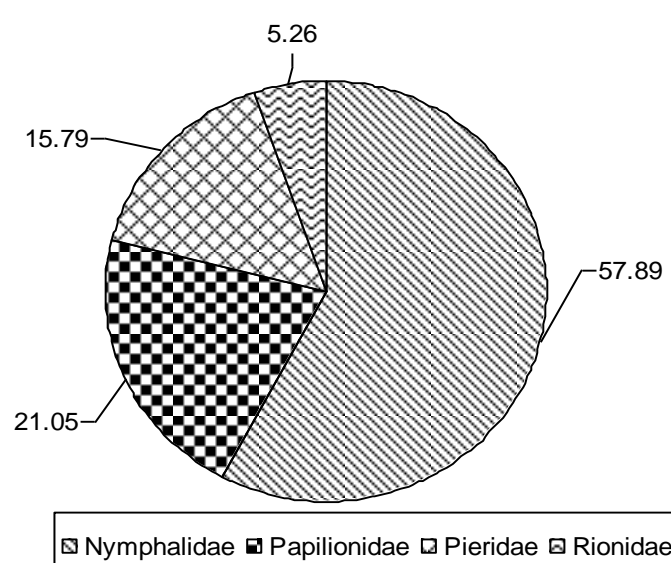

Gambar 1. Persentase Famili Kupu-kupu Berdasarkan Spesies 


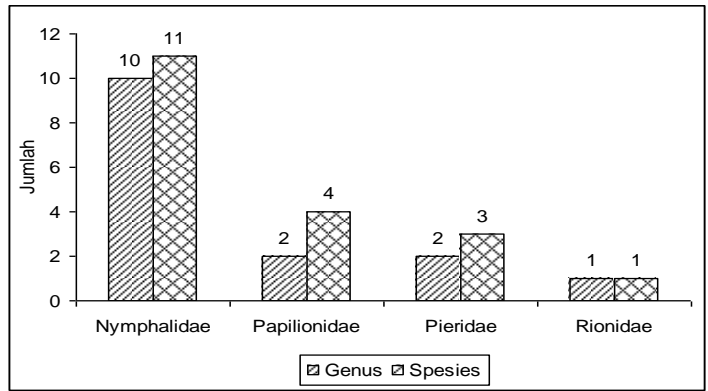

Gambar 2. Jumlah Genus dan Spesies Kupukupu dari Tiap Famili

Jumlah spesies yang ditemukan di Pulau Mantehage baru mencapai 1,19\% dari seluruh spesies kupu-kupu yang ditemukan di Indonesia (1.600 spesies). Hasil ini juga lebih rendah jika dibandingkan dengan spesies kupu-kupu yang terdapat di Pulau Manado Tua, Sulawesi Utara yang memiliki 29 spesies (Koneri dan Saroyo, 2012). Perbedaan jumlah spesies kupu-kupu yang ditemukan tergantung pada keanekaragaman tumbuhan sebagai tanaman inang kupu-kupu tersebut. Spesies paling sedikit ditemukan pada suatu habitat disebabkan kurangnya tanaman inang yang menjadi sumber makanan dari kupu-kupu. Faktor lain yang mempengaruhi kekayaan spesies kupu-kupu pada suatu habitat yaitu suhu, kelembaban, curah hujan, cahaya, predator dan parasit. Menurut Vane-Wright \& de Jong (2003) keberhasilan kolonisasi kupu-kupu tergantung pada habitat yang sesuai, dalam hal ini ketersediaanya sumber makanan

Faktor lain penyebab sedikitnya jumlah kupu-kupu yang ditemukan pada suatu pulau tergantung pada luas pulau tersebut. Jika dibandingkan maka Pulau Manado Tua (1.028,27 ha) jauh lebih besar daripada Pulau Mantehage (738,10 ha). Jumlah spesies kupukupu yang ditemukan di daratan utama Pulau Sulawesi lebih banyak jika dibandingkan dengan hasil penelitian yang diperoleh. Hasil penelitian Amir et al., (1993) di Bantimurung Sulawesi Selatan ditemukan 56 jenis kupukupu. Hal ini sesuai dengan Teori Biogeografi Pulau yang meyebutkan bahwa pulau-pulau yang kecil dan jauh dari daratan utama mendukung lebih sedikit spesies dibandingkan dengan pulau-pulau yang besar dan dekat dengan daratan utama (Sumarto \& Siahaan (2012).

Famili Nymphalidae banyak ditemukan karena famili ini merupakan terbesar jumlahnya dalam Ordo Lepidoptera. Famili
Nymphalidae umumnya mempunyai penyebaran yang luas, menyukai tempat yang terang, daerah kebun, hutan dan juga menyukai buah yang busuk (Dendang, 2009). Banyaknya jumlah famili Nymphalidae yang ditemukan di Pulau Mantehage karena terdapat beberapa tumbuhan yang sesuai untuk mendukung kehidupan kupu-kupu famili Nymphalidae, baik sebagai sumber makanan maupun sebagai tempat untuk berlindung. Menurut penelitian Dendang (2009), tanaman inang dari famili Nymphalidae yaitu Annonaceae, Asteraceae, Moraceae, Rubiaceae dan Anacardiaceae. Spesies tumbuhan yang ditemukan di Pulau Mantehage yaitu tembelekan (Asteraceae), kenanga (Annonaceae), mangga (Anacardiaceae), beringin (Moraceae), lemon (Rutaceae) dan kayu mas (Rubiaceae).

Perbedaan kelimpahan spesies kupukupu yang ditemukan dapat disebabkan oleh kurangnya tanaman tanaman inang yang menjadi sumber makanan dari spesies kupukupu tersebut. Keberhasilan kolonisasi kupukupu tergantung pada habitat yang sesuai, dalam hal ini ketersediaan sumber makanan (Vane-Wright \& de Jong. 2003). Spesies Catopsilia scylla asema dan Catopsilia pamona flava memiliki kelimpahan tertinggi karena bersifat polifagus dan tersedianya sumber makanan (food plant) dan pohon inang (host plant) sebagai sumber makanan dan tempat untuk meletakan telur kupu-kupu (Effendi, 2009). Menurut Peggie dan Amir (2006), tanaman inang dari spesies Catopsilia scylla asema dan Catopsilia pamona flava, yaitu Caesalpiniacea (Cassia, Senna, Bauhinia, Brownea), Capparaceae (Crateva), Papilionaceae (Butea, Pterocarpus, Sesbania).

\section{KESIMPULAN}

Jumlah spesies kupu-kupu yang ditemukan di Pulau Mantehage sebanyak 4 famili, 19 spesies an 332 individu. Famili yang paling banyak didapat yaitu Nymphalidae, sedangkan famili yang paling sedikit yaitu Famili Riodinidae. Kelimpahan spesies kupu-kupu tertinggi yaitu pada Catopsilia scylla asema (16,57\%) dan Catopsilia pamona flava $(15,06 \%)$ Spesies yang kelimpahannya terendah yaitu Danaus ismare alba (0,30\%), Lohara dexamenus $(0,30 \%)$, dan Graphium agamemnon $(0,30 \%)$. 


\section{DAFTAR PUSTAKA}

Achmad, A. 2002. Potensi Dan Sebaran Kupu-Kupu di Kawasan Taman Wisata Alam Bantimurung. Badan Penelitian dan Pengembangan Kehutanan Balai Penelitian Kehutanan Makassar, Makasar.

Amir, M., W. A. Noerdjito and R. Ubaidillah. 1993. Butterflies of Bantimurung, South Sulawesi. International Butterfly Conference, Ujung Pandang.

Borror, B.J., C.A. Triplehorn and N.F. Johnson. 1996. Pengenalan Pelajaran Serangga. Edisi ke-6. Gajah Mada University Press, Yogyakarta.

Dendang, B. 2009. Keanekaragaman KupuKupu di Resort Selabintana Taman Nasional Gunung Gede Pangrango, Jawa Barat. Jurnal Penelitian dan Konservasi Alam 4(1) 25-36.

Effendi, M.A. 2009. Keragaman Kupu-Kupu (Lepidoptera : Ditrysia) di Kawasan "Hutan Koridor" Taman Nasional Gunung Halimun-Salak Jawa Barat. Institut Pertanian Bogor. Bogor.

Koneri, R. 2008. Pengaruh Fragmentasi Habitat Terhadap Keragaman Serangga. Fakultas Matematika dan Ilmu Pengetahuan Alam. Universitas Sam Ratulangi. Manado. Pacific Journal 2(2) : 137-141.

Koneri, R dan Saroyo. 2011. Keanekaragaman Kupu-Kupu (Lepidoptera) Pada Empat Tipe Habitat di Hutan Lindung Gunung Klabat, Sulawesi Utara. Biosfera 28(2) Hal 86-94.

Koneri, R dan Saroyo. 2012. Distribusi dan Keanekaragaman Kupu-Kupu (Lepidoptera) di Gunung Manado Tua, Kawasan Taman Nasional Laut Bunaken, Sulawesi Utara. Jurnal Bumi Lestari 12(2): 357-365.

Mehta, A. 1999. Buku Panduan Lapangan Taman Nasional Bunaken. Balai TNB, NRM/EPIQ dan Yayasan Kelola. Manado.
Noerdjito, W.A., Amir, M. 1992. Kekayaan Kupu-Kupu di Cagar Alam Bantimurung Sulawesi Selatan dan Sekitarnya. PPPSDH Pustlitbang Biologi, LIPI : 330-337

Peggie, D dan Amir. 2006. Panduan Praktis Kupu-Kupu di Kebun Raya Bogor. Pusat Penelitian Biologi, LIPI. Cibinong.

Sumarto, S dan Siahaan, P. 2012.

Biogeografi. Penerbit Alfabeta.

Bandung.

Vane-Wright, R.I., and de Jong, R. 2003. The Butterflies of Sulawesi: annotated checklist for a critical island fauna. Zool. Verh. Leiden 343 : 3-267.

Widhiono. 2004. Dampak Modifikasi Hutan Terhadap Keragaman Hayati KupuKupu di Gunung Slamet Jawa Tengah. Biosfera 21(3) : 89-94. 